\title{
Ağız kokusu farkındalığının anket uygulayarak belirlenmesi ve farklı diş macunlarının ağız kokusuna etkisinin halimeter ile ölçülerek değerlendirilmesi
}

\section{Determination of oral malodor awareness by applying a questionnaire and evaluation of the effect of different toothpastes on the oral malodor by halimeter}

\author{
Şafak Necati DÖNERTAŞ*回 ibrahim Levent TANER 回
}

Gazi Üniversitesi Diş Hekimliği Fakültesi, Periodontoloji Anabilim Dalı Ankara/TÜRKiYE

\section{Öz}

Amaç: Halitozis, her yaştan bireyleri etkileyebilen yaygın bir problemdir. Bu çalışmayla ağız kokusu farkındalığını anket ve halimeter ölçümlerini birlikte değerlendirerek tespit etmeyi ve farklı etken madde içeren diş macunlarının ağız kokusu üzerine etkilerini incelemeyi amaçladık.

Gereç ve Yöntemler: Çalışmaya Gazi Üniversitesi Diş Hekimliği Fakültesi'nde öğrenim gören 1-2 ve 3. sınıftan toplam 308 öğrenci dahil edildi. Çalışma öncesi tüm hastalardan sözlü ve yazılı onamları alındı. Anket sonrası farklı derecede ağız kokusuna sahip olduğunu düşünen 100 birey iki eşit gruba ayrıldı. Etken maddesi çinko ve kalay olan iki diş macunu grubu ellişer bireyden oluştu. Bu bireylerden başlangıç ( $\mathrm{t} 1$ ), bir ay sonra (t2) ve üç ay sonra (t3) olmak üzere üç kez periodontal ölçümler ve ağız kokusu ölçümleri tekrarlandı. Ağız kokusunun belirlenmesinde organoleptik yöntem ve portatif sülfür monitörü (Halimeter $\left.{ }^{\oplus}\right)$ kullanıldı. Elde edilen tüm veriler istatistiksel yöntemlerle incelendi.

Bulgular: Ağız kokusunun var olduğunu düşünen ve hissedilen ağız kokusu seviyesini 0-5 arasında derecelendiren hastalarda, organoleptik skorlar (OLS) ve halimeter değerleri (HMD) anlamlı derecede yüksek bulundu $(p<0,001)$. Ağız kuruluğu olan hastalarda OLS ve HMD daha yüksek bulundu $(p<0,05)$. Ağız solunumu yapan hastalarda HMD yüksek bulundu $(p<0,05)$. DMFT ile OLS ve HMD arasında anlamlı bir ilişki saptandı $(p<0,001)$. Farklı macun kullanan iki test grubundan elde edilen indeksler ve ağız kokusu ölçümleri arasında anlamlı bir fark bulunamadı ( $p>0,05)$.

Sonuç: Çalışma grubumuzun ağız kokusu farkındalıkları yüksek bulundu. Çinko ve kalay içeren diş macunları ağız kokusu seviyelerini azaltmada etkili olduğu istatistiksel olarak biri diğerine göre daha üstün bulunamadı.

Anahtar kelimeler: ağız kokusu; halitozis; halimeter; çinko; kalay

Sorumlu Yazar*: Şafak Necati Dönertaş Gazi Üniversitesi Diş Hekimliği Fakültesi, Periodontoloji Anabilim Dalı Ankara/TÜRKiYE 


\begin{abstract}
Aim: Halitosis is a common problem that can affect individuals of all ages. In this study, we aimed to determine the awareness of halitosis by evaluating the questionnaires and halimeter measurements together and to determine the effects on the halitosis level of toothpastes containing different active substances.
\end{abstract}

Material and Methods: A total of 308 students from the 1st, 2nd and 3rd year students of Gazi University Faculty of Dentistry were included in the study. Oral and written informed consent were obtained from all patients before the study. After the questionnaire was applied, 100 students were divided into two equal groups. The toothpaste group consisting of active substance zinc and the toothpaste group with active substance stannous consisted of 50 individuals. Periodontal measurements and halitosis measurements were repeated three times, from these individuals at the beginning ( $\mathrm{t} 1$ ), at one month (t2) and at three months (t3). Organoleptic method and portable sulfur monitor (Halimeter ${ }^{\circledR}$ ) were used to determine the halitozis. All data were analyzed with statistical methods.

Results: Organoleptic scores (OLS) and halimeter values (HMD) were found significantly higher in patients who thought to halitosis ( $p<0.001)$. OLS and HMD were higher in patients who felt dryness in their mouth ( $p<0.05)$. HMD was higher in mouth breathing patients $(p<0.05)$. There was a significant relationship between DMFT and OLS and HMD ( $p<0.001)$. No significant difference was found between the periodontal indeces and halitosis measurements obtained from two test groups using different toothpastes ( $p>0.05)$.

Conclusion: In our study group, halitosis awareness was found to be high. Although toothpastes containing zinc and stannous are effective in reducing halitosis levels, it is not possible to mention that one is more effective than the other.

Keywords: bad breath; halitosis; halimeter; zinc; stannous

\section{Giriş}

Kötü ağız kokusu dünyanın birçok yerinde yaşanılan ortak bir problemdir ve nefes kokusunun bozuk veya hoş olmaması olarak tanımlanmaktadır [1]. Halitozis, breath odor, malodor, oral malodor, bromopnea, fetor ex ore, fetor oris, ozostomia, stomatodysodia ve bad breath terimleri ağız kokusunu tanımlamak için sıklıkla kullanılmaktadır [2]. Ağız kokusunun etiyolojisinde hem ağız içi (intraoral) hem de ağız dışı (extraoral) etkenler yer alır. Ağız kokusu çoğunlukla ağız içi nedenlere bağlı olarak oluşmaktadır [3]. Ağız kaynaklı halitozisin nedenleri genel olarak kötü ağız hijyeni, dili kaplayan eklentilerin varlığı, periodontal hastalıklar, periimplant hastalıklar, derin çürük lezyonları, ekspoz olmuş nekrotik diş pulpaları, perikoronitis, mukozal ülserasyonlar, iyileşmekte olan yaralar, food impaction varlığı, plak birikimi, hatalı yapılmış restorasyonlar, gece boyunca ağızda kalan ve temiz olmayan protezler, tükürük akış hızını azaltan faktörlerdir [4]. Ağız kokusu periodontitis ile ilişkili olsa da periodontal sağlıklı bireyler de önemli seviyede ağız kokusuna sahiptir. Son zamanlarda dil sırtı ağız kokusunun ana kaynağı olarak gösterilmiştir. Bu, dilin deskuame epitel hücrelerini ve ölü lökositleri tutan papiller yapısıyla ve geniş yüzey alanıyla ilişkilidir [5]. Halitozisin oluşumunda aminoasitlerin bakteriyel yıkımı sonucu oluşan uçucu sülfür bileşikleri (USB); hidrojen sülfür, metil merkaptan ve dimetil sülfür en önemli rolü oynar [1]. USB üretimi özellikle tükürükteki, dişeti oluğundaki, dildeki ve ağzın diğer alanlarındaki mevcut mikroorganizmaların serbest olarak bulunan sistein, sistin ve methionin gibi sülfür içeren aminoasit veya protein substratlarının proteolizisi sonucunda olur. Ağız boşluğunda yer alan eksfoliye olmuş epitel hücreleri ve dağılmış lökositler bu gibi substratların en önemli kaynağıdır [6]. Halitozis her yaştan insanı etkileyebilen, yaygın bir problemdir. Şiddetli veya uzun süreli olduğu durumlarda, kişinin kendine güveninin ve sosyal etkileşimlerinin azalmasına yol açabilir [7]. Günümüzde sosyal ilişkiler bu kadar ön plandayken ağız kokusu önemli bir sosyal problem olarak karşımıza çıkmaktadır. Bu nedenle hem sosyal hem de tıbbi açıdan, ağız kokusunun doğru teşhisi ve altta yatan nedenin tedavisi için kesin bir çözüm üretilmesi gerekmektedir.

Yaptığımız bu çalışma ile Gazi Üniversitesi Diş Hekimliği Fakültesi'nde okuyan öğrencilerin ağız kokusu farkındalığını tespit etmeyi ve aynı zamanda çinko ve kalay içeren diş macunlarının ağız kokusu üzerine etkilerini gözlemsel olarak incelemeyi amaçladık.

\section{Gereç ve Yöntemler}

\section{Çalışma Popülasyonu}

Bu çalışmaya Gazi Üniversitesi Diş Hekimliği Fakültesi'nde öğrenim görmekte olan, ağız kokusu şikayeti olan veya olmayan 1,2 ve 3. sınıftaki 308 birey dahil edildi. Araştırmaya katılan tüm bireylere çalışmanın nedeni ile birlikte gerekli tüm bilgiler detaylı olarak anlatıldıktan sonra çalışmaya başlamadan önce hastaların yazılı onamları alındı. Tüm bireylere oral hijyen eğitimi ve yumuşak diş fırçası verildi. Araştırmamı için Gazi Üniversitesi Etik Komisyonu tarafından onay verilmiştir. (19 
Aralık 2017 tarih ve 10 sayılı toplantısı / araştırma kod no: 2017-497)

\section{Anket Planlanması}

Tüm katılımcıların rahatlıklıkla anlayacağı bir dilde anket hazırlandı. Uygulanan anket formu ile hastaların cinsiyet, yaş gibi temel bilgilerle beraber ağız kokusu şikayetinin varlığı ya da yokluğu, var ise ilk ne zaman farkedildiği ve ne derecede hissedildiği gibi hastaların farkındalığını ölçecek sorular soruldu. Ağız kuruluğu ya da ağız solunumu problemi olup olmadığı kaydedildi. Anketin devamında diş fırçalama sıklığı, dil temizleme, diş ipi ve gargara kullanımı gibi oral hijyen alışkanlıkları sorgulandı.

\section{Ağız Kokusunun Ölçümü}

Çalışmaya katılan bireylerden ağız kokusu ölçümü yapılırken organoleptik yöntemler ile taşınabilir bir sülfür monitörü olan halimeter cihazı kullanıldı. Tüm hastalardan ağız kokusu ölçümleri sabah 08:30-12:30 saatleri arasında yapıldı. Ölçüm yapılacak bireyler, son 48 saat içinde ağız kokusuna sebep olabilecek gıdaları tüketmemeleri, son 12 saatte alkol almamaları ve 2 saat içerisinde herhangi bir gıda ürünü, sigara, çay, kahve tüketmemeleri konusunda uyarıldılar.

\section{Klinik Muayene}

Yapılan işlemlerin ağız kokusunu etkileme olasılığı göz önünde bulundurularak, klinik muayeneler halitozis değerlendirilmelerinden sonra yapıldı. Tüm periodontal indeks ölçümleri kaydedildi. Ağız içi muayenede WHO kriterleri esas alınarak DMFT (Decayed, Missing and Filled Teeth Index) indeksi alındı. Dili kaplayan eklenti (DKE) miktarları belirlenirken Miyazaki ve arkadaşlarının 1995 yılında tanımladıkları dil kaplama indeksinden (Tongue Coating Index, TCI) faydalanıldı.

\section{İstatistiksel Analiz}

Veriler IBM SPSS V23 ile analiz edildi. Normal dağılıma uygunluk Shapiro Wilk ile incelendi. Normal dağılım gösteren verilerin karşılaştırılmasında bağımsız örnekler t testi ile tek yönlü varyans analizi kullanıldı. Normal dağılmayan verilerin karşılaştırılmasında ise Mann Whitney $U$ testi ile Kruskal Wallis testi kullanıldı. Kategorik veriler kikare testi ile incelendi. Değişkenler arasındaki ilişki ise Spearman sıra korelasyonu ile incelendi. Analiz sonuçları normal dağılan veriler için ortalama \pm s.sapma, normal dağılmayan veriler için ortanca (min-mak) olarak sunuldu. Kategorik veriler ise frekans (yüzde) olarak ifade edildi. Önem düzeyi $p<0,05$ olarak alındı.

\section{Bulgular}

Çalışma popülasyonu yaş ortalaması 20 olan 308 katılımcıdan oluşmaktadır. Katılımcılar ankette verilen tüm soruları yanıtladılar. Ankete katılan 308 bireyin \%66,2'si kadındır.
Katılımcıların \%39'u ağız kokusundan şikayetçidir. 0 ile 5 arasında değişen ağız kokusu yoğunluğu seçeneklerinden katılımcıların \%51'i mevcut ağız kokusu yoğunluğunu 2 olarak düşünmektedirler. Katılımcıların \%96,4'i ağız kokusunun kesintili olduğunu, \%92,9'u ağız kokusunu kendisi fark ettiğini ifade etmiştir. Katılımcıların \%89,6'sında ağız kokusu sabah saatlerinde olmaktadır. Katılımcıların \%33,4'ü ağız kuruluğu hissetmektedir. Katılımcıların \%52,3'ü ağızdan nefes alıp vermektedir. (Tablo 1)

\begin{tabular}{|c|c|c|}
\hline & Frekans & Yüzde \\
\hline \multicolumn{3}{|l|}{ Cinsiyet } \\
\hline Erkek & 104 & 33,8 \\
\hline Kadın & 204 & 66,2 \\
\hline \multicolumn{3}{|c|}{ Size göre ağzınız kokuyor mu? } \\
\hline Evet & 120 & 39,0 \\
\hline Hayır & 188 & 61,0 \\
\hline \multicolumn{3}{|c|}{$\begin{array}{l}\text { Ağız kokunuzun ne kadar yoğun } \\
\text { olduğunu düşünüyorsunuz? }\end{array}$} \\
\hline 1 & 59 & 19,2 \\
\hline 2 & 157 & 51,0 \\
\hline 3 & 70 & 22,7 \\
\hline 4 & 22 & 7,1 \\
\hline
\end{tabular}

Ağız kokunuz başladığından bugüne

kadar sürekli mi var yoksa kesintili

olarak mı devam ediyor?

\begin{tabular}{l|ll} 
Sürekli var & 11 & 3,6 \\
Kesintili & 297 & 96,4
\end{tabular}

Ağız kokunuz olduğunu nasıl

öğrendiniz?

\begin{tabular}{|l|l|l|}
\hline Birilerinin söylemesiyle & 22 & 7,1 \\
\hline Kendim fark ettim & 286 & 92,9
\end{tabular}

Koku günün en çok hangi saatlerinde oluyor?

\begin{tabular}{|l|l|l|}
\hline Sabah & 276 & 89,6 \\
\hline Öğlen & 24 & 7,8 \\
\hline Akşam & 8 & 2,6 \\
\hline
\end{tabular}

Sabahları uyandığınızda duyduğunuz ağız kokusu iki saat içerisinde kayboluyor mu?

\begin{tabular}{l|ll} 
Evet & 289 & 93,8 \\
Hayır & 19 & 6,2
\end{tabular}

Ağız kuruluğunuz var mı?

\begin{tabular}{|c|c|c|}
\hline Evet & 72 & 23,4 \\
\hline Hayır & 236 & 76,6 \\
\hline \multicolumn{3}{|c|}{ zdan nefes alıp veriyor musunuz? } \\
\hline Evet & 147 & 47,7 \\
\hline Hayır & 161 & 52,3 \\
\hline
\end{tabular}




\begin{tabular}{|c|c|c|}
\hline & \multicolumn{2}{|c|}{ Ortanca(min-mak) } \\
\hline & \multicolumn{2}{|c|}{ OLS-t1 HMD-t1 } \\
\hline \multicolumn{3}{|l|}{ Cinsiyet } \\
\hline Erkek & $2(1-3)$ & $140(68-328)$ \\
\hline Kadın & $2(0-3)$ & $138(38-275)$ \\
\hline Test istatistiği & $U=1021,5$ & $\mathrm{U}=1021$ \\
\hline $\mathrm{p}$ & 0,359 & 0,400 \\
\hline \multicolumn{3}{|c|}{ Size göre ağzınız kokuyor mu? } \\
\hline Evet & $3(0-3)$ & $180,89 \pm 61,81$ \\
\hline Hayır & $2(0-3)$ & $122 \pm 32,97$ \\
\hline Test istatistiği & $U=767$ & $\mathrm{~T}=68,28$ \\
\hline$p$ & $<0,001$ & $<0,001$ \\
\hline \multicolumn{3}{|c|}{$\begin{array}{l}\text { Ağız kokunuzun ne ka- } \\
\text { dar yoğun olduğunu } \\
\text { düşünüyorsunuz? }\end{array}$} \\
\hline 1 & $2(1-3) a$ & $107,1 \pm 30,5 a$ \\
\hline 2 & $2(0-3) a$ & $124,3 \pm 30,1 \mathrm{a}$ \\
\hline 3 & $3(1-3) b$ & $185,2 \pm 58,9 b$ \\
\hline 4 & $3(2-3) b$ & $215,1 \pm 50,8 b$ \\
\hline Test istatistiği & $\mathrm{U}=36,481$ & $\mathrm{~F}=14,955$ \\
\hline $\mathrm{p}$ & $<0,001$ & $<0,001$ \\
\hline \multicolumn{3}{|c|}{ Ağız kuruluğunuz var mı? } \\
\hline Evet & $3(1-3)$ & $166(63-272)$ \\
\hline Hayır & $2(0-3)$ & $131,5(38-328)$ \\
\hline Test istatistiği & $\mathrm{U}=786$ & $U=680$ \\
\hline$p$ & 0,030 & 0,005 \\
\hline \multicolumn{3}{|c|}{$\begin{array}{l}\text { Ağızdan nefes alıp veriyor } \\
\text { musunuz? }\end{array}$} \\
\hline Evet & $3(1-3)$ & $152(67-328)$ \\
\hline Hayır & $2(0-3)$ & $131,5(38-275)$ \\
\hline Test istatistiği & $U=992$ & $\mathrm{~T}=952,5$ \\
\hline p & 0,058 & 0,045 \\
\hline
\end{tabular}

\begin{tabular}{|c|c|c|c|}
\hline \multirow{4}{*}{ DMFT } & & OLS-t1 & HMD-t1 \\
\hline & $r$ & 0,518 & 0,630 \\
\hline & $p$ & $<0,001$ & $<0,001$ \\
\hline & $\mathrm{N}$ & 100 & 100 \\
\hline
\end{tabular}

OLS-t1 ve HMD-t1 cinsiyete göre farklılık göstermemektedir. ( $p$ değerleri sırasıyla 0,359, 0,400). OLS-t1 ve HMD-t1, ağız kokusu şikayetinin varlığına göre farklılık göstermektedir ( $p$ değerleri sırasıyla $<0,001,<0,001)$. Ağız kokusu olduğunu söyleyen kişilerde OLS-t1 ortalama değeri 3, HMD-t1 ortalama değeri 180,89 olarak elde edilmiştir. Ağız kokusu olmadığını söyleyen kişilerde OLS-t1 ortalama değeri 2, HMD-t1 ortalama değeri 122 olarak elde edilmiştir. OLS-t1 ve HMD-t1, hissedilen mevcut ağız kokusu yoğunluğuna göre farklılık göstermektedir ( $p$ değerleri sırasıyla $<0,001,<0,001$ ). Bu farklılıklar 1 ve 2 diyen grubun OLS-t1 ve HMD-t1 ortalama değerlerinin 3 ve 4 diyenlere göre daha düşük elde edilmesinden kaynaklanmaktadır. OLS-t1 ve HMD-t1 ağız kuruluğu varlığına göre istatistiksel olarak anlamlı farklılık göstermektedir ( $p$ değerleri sırasıyla 0,030, 0,005). Ağız kuruluğu olan kişilerde OLS-t1 ortalama değeri 3, olmayanlarda ise 2 olarak elde edilmiştir. Ağız kuruluğu olan kişilerde HMD-t1 ortalama değeri 166, olmayanlarda 131,5 olarak elde edilmiştir. OLS-t1 ağızdan nefes alıp verme durumuna göre farklılık göstermemektedir $(p=0,058)$. HMD-t1 ise ağızdan nefes alıp verme durumuna göre farklılık göstermektedir $(p=0,045)$. Ağızdan nefes alıp verenlerde ortalama değer 152, ağızdan nefes alıp vermeyenlerde 131,5 olarak elde edilmiştir. (Tablo 2 ) DMFT ile OLS ve HMD arasında pozitif yönlü orta düzey anlamlı bir ilişki saptanmıştır. (Tablo 3)

Periodontal indeksler ve DKE ile OLS ve HMD'ler arasında tüm ölçüm zamanlarında istatistiksel olarak pozitif yönlü (zayıf, orta ya da güçlü düzeyde) anlamlı bir ilişki bulunmuştur. (Tablo 4)

Etken maddesi çinko ve kalay olan diş macunu kullanan çalışma grupları incelendiğinde 3. Ay sonunda başlangıç ölçüm değerlerine göre hem periodontal parametrelerde hem de ağız kokusu ölçüm değerlerinde azalma olduğu tespit edilmiştir. Gruplar arasında ise istatistiksel olarak anlamlı bir farklılık yoktur. (Tablo 5)

\begin{tabular}{|c|c|c|c|c|c|c|}
\hline \multicolumn{7}{|c|}{$\begin{array}{l}\text { Tablo 4. Periodontal indeksler ve DKE ile OLS ve HMD'ler } \\
\text { arasındaki ilişkinin incelenmesi }\end{array}$} \\
\hline Pì-t1 & OLS-t1 & OLS-t2 & OLS-t3 & HMD-t1 & HMD-t2 & HMD-t3 \\
\hline Pi-t2 & $0,557^{*}$ & & & $0,635^{*}$ & & \\
\hline Pi-t3 & & $0,493^{*}$ & & & $0,584^{* *}$ & \\
\hline Gi-t1 & & & $0,508^{*}$ & & & $0,454^{*}$ \\
\hline Gi-t2 & $0,531^{*}$ & & & $0,614^{*}$ & & \\
\hline $\mathrm{Gi}-\mathrm{t} 3$ & & & $0,318^{*}$ & & & $0,203^{*}$ \\
\hline CD-t1 & $0,304^{*}$ & & & $0,341^{*}$ & & \\
\hline CD-t2 & & $0,221^{*}$ & & & $0,235^{* *}$ & \\
\hline CD-t3 & & & $0,335^{*}$ & & & $0,247^{*}$ \\
\hline SK-t1 & $0,791^{*}$ & & & $0,819^{*}$ & & \\
\hline SK-t2 & & $0,650^{*}$ & & & $0,721^{*}$ & \\
\hline SK-t3 & & & $0,560^{*}$ & & & $0,601^{*}$ \\
\hline DKE-t1 & $0,591^{*}$ & & & $0,727^{*}$ & & \\
\hline DKE-t2 & & $0,634^{*}$ & & & $0,723^{*}$ & \\
\hline DKE-t3 & & & $0,573^{*}$ & & & $0,631^{*}$ \\
\hline
\end{tabular}




\begin{tabular}{|c|c|c|c|c|}
\hline & Grup1 (Çinko) & Grup2 (Kalay) & Test İstatistiği & $p$ \\
\hline PI-t1 & $1,14 \pm 0,34$ & $0,96 \pm 0,3$ & $t=2,713$ & 0,008 \\
\hline Pi-t2 & $0,74 \pm 0,27$ & $0,64 \pm 0,25$ & $t=1,855$ & 0,067 \\
\hline PI-t3 & $0,41(0,13-0,96)$ & $0,34(0,11-0,84)$ & 961,5 & 0,047 \\
\hline Gi-t1 & $1,03(0,56-1,29)$ & $0,96(0,48-1,48)$ & 1168 & 0,572 \\
\hline Gi-t2 & $0,76 \pm 0,15$ & $0,72 \pm 0,19$ & $t \_1,026$ & 0,307 \\
\hline Gi-t3 & $0,61(0,29-0,83)$ & $0,44(0,26-0,72)$ & 695,5 & $<0,001$ \\
\hline CD-t1 & $1,78(1,42-2,21)$ & $1,81(1,44-2,17)$ & 1360 & 0,448 \\
\hline CD-t2 & $1,64 \pm 0,16$ & $1,65 \pm 0,14$ & $t=-0,552$ & 0,582 \\
\hline CD-t3 & $1,52(1,16-1,79)$ & $1,51(1,16-1,73)$ & 1169 & 0,576 \\
\hline SK-t1 & $3,57(0,89-6,25)$ & $2,67(0-5,35)$ & 963,5 & 0,043 \\
\hline SK-t2 & $1,78(0-4,46)$ & $1,78(0-3,57)$ & 1018,5 & 0,101 \\
\hline SK-t3 & $0,89(0-2,67)$ & $0,89(0-2,89)$ & 1169 & 0,545 \\
\hline OLS-t1 & $2(0-3)$ & $2(0-3)$ & 1122,5 & 0,336 \\
\hline OLS-t2 & $2(0-3)$ & $2(0-3)$ & 1129,5 & 0,336 \\
\hline OLS-t3 & $1(0-2)$ & $1(0-2)$ & 1245,5 & 0,972 \\
\hline HMD-t1 & $155,9 \pm 65,69$ & $143,46 \pm 45,93$ & $t=1,097$ & 0,275 \\
\hline HMD-t2 & $98,48 \pm 41,62$ & $114,14 \pm 38,73$ & $t=-1,948$ & 0,054 \\
\hline HMD-t3 & $75,02 \pm 35,94$ & $90,96 \pm 34,35$ & $t=-2,267$ & 0,026 \\
\hline
\end{tabular}

\section{Tartışma}

Çalışmamızda ağız kokusu seviyesini belirlemek için, organoleptik değerlendirme ile beraber Halimeter cihazı kullanılmıştır. Halimeter taşınması, uygulaması ve değerlendirilmesi kolay olduğundan dolayı çalışmamızda tercih edilmiştir. Organoleptik değerlendirmelerde ise Rosenberg tarafından tanımlanmış olan organoleptik ölçüm skalasına göre skorlama yapılmıştır [8]. Lu ve ark., Quirynen ve ark. yaptıkları çalışmalarda organoleptik değerlendirme ile halimeter ölçümleri arasında anlamlı bir ilişki olduğunu bildirmişlerdir $[9,10]$.

Halitozis her yaştan insanı etkileyebilmektedir. Ağız kokusunun görülme sıklığı ve şiddetinin sağlıklı bireylerde yaşa bağlı olarak arttığını gösteren birçok çalışma bulunmaktadır. Miyazaki ve arkadaşlarının 2672 katılımcıyla yaptıkları bir çalışmada USB değerleri ile cinsiyet arasında anlamlı bir ilişki bulunmamıştır ancak farklı yaş gruplarında tespit edilen ağız kokusu seviyeleri anlamlı farklılık göstermiş̧ir. Ağız kokusu değerlerini en düşük 15-34 yaş, en yüksek 35-64 yaş grubu bireylerde tespit etmişlerdir [11]. Bizim çalışmamızda ise yaş ortalaması 20 olan diş hekimliği öğrencileri araştırmaya dahil edilerek yaş farkından doğabilecek olan farklılıklar standardize edilmeye çalışılmıştır.

Bireyler bazen ağız kokusu olduğu halde bunun farkında olmayabildiği gibi ağız kokusu olmadığı halde sürekli bir ağız kokusundan şikayet edebilmektedirler. Bu durum bireylerin ağız kokusu farkındalıkları ile ilgilidir. Rosenberg ve ark., Bornstein ve ark. yaptıkları çalışmalarda bireylerin ağız kokusu şikayeti ile organoleptik skorlar ve USB değerleri arasında istatistiksel olarak anlamlı bir ilişki tespit edememişlerdir [12, 13]. Çalışmamızın sonuçlarına göre ağız kokusunun var olduğu düşüncesi ile OLS ve HMD arasındaki ilişki istatistiksel olarak anlamlıdır $(p<0,05)$. Aynı şekilde hissedilen ağız kokusu yoğunluğu ile OLS ve HMD arasında da anlamlı bir ilişki vardır $(p<0,05)$. Iwanicka-Grzegorek ve ark. yaptıkları çalışma ile bulgularımızı destekleyecek şekilde ağız kokusu şikayeti ile USB'ler arasında anlamlı ilişki bulmuşlardır [14].

Amir [15] ve Nalçacı [16] ağız kokusu ve DMFT indeksleri arasında pozitif bir ilişki bulmuşlardır. Liu ve ark. ile Miyazaki ve ark. ise DMFT indeksi ile yüksek USB değerleri arasında bir ilişki tespit edememişlerdir $[4,11]$. Bizim çalışmamızda DMFT değerleri ile hem OLS-t1 hem de HMD-t1 arasında pozitif yönlü orta düzey anlamlı bir ilişki bulunmuştur ( $p<0,05)$. Bu durum kavitasyon oluşmuş çürüklerin ve uygun yapılmamış restorasyonların ağızdaki plak ve gıda retansiyon alanlarını artırmasının bir sonucu olabilir.

Literatürde ağız solunumu ve ağız kuruluğunun halitozis oluşumunda etkili olduğunu savunan birçok çalışma bulunmaktadır. Çiçek ve ark. ile Nalçacı ve ark. yapmış oldukları çalışmaların sonucunda ağız kuruluğu ve ağız solunumunun ağız kokusu üzerinde etkili olduğunu bildirmişlerdir [17, 18]. Suzuki ve ark. ise ağız solunumu ile USB ve OLS arasında herhangi bir ilişki olmadığını belirtmişlerdir [19]. Bizim çalışmamızın sonucuna göre ağız kuruluğu ile OLS ve HMD arasında anlamlı bir ilişki vardır ( $p<0,05)$. Ağız solunumu ile OLS arasında anlamlı bir sonuç bulunmamasına karşın ( $p>0,05)$, ağız solunumu ve HMD arasında istatistiksel olarak anlamlı bir ilişki saptanmıştır $(p<0,05)$.

Periodontal hastalık ve ağız kokusu ilişkisi en çok tartışılan konulardan biridir. Ağız kokusu oluşumunda etkili olan USB'lerin periodontal hastalığın patogenezinde önemli rol oynaması, her ikisinin de ileri yaşa bağlı olarak artış göstermesi, etiyolojilerindeki bakteriyel komponentlerden dolayı aralarında kuvvetli bir ilişki bulunmaktadır. Çalışmamıza katılan bireyler periodontal olarak sağlıklı ya da gingivitisli hastalardır. Hastalardan başlangıçta, 1 ay sonra ve 3 ay sonra olmak üzere üç kez plak indeksi (Pi), gingival indeks (Gi), cep derinliği (CD), sondlamada kanma (SK) ve DKE ile beraber OLS ve HMD'leri kayıt altına alınmıştır. İstatistiksel analizler sonucunda her üç ölçüm zamanında da periodontal parametreler ile ağız kokusu seviyeleri arasında pozitif yönlü anlamlı bir ilişki bulunmuştur. Bu sonuç bize periodontal durumun ağız kokusu üzerinde etkili olduğunu göstermektedir. Tonzetich, 1978 yılında yaptığı çalışmasında USB üretiminin, periodontal cep derinliği ve 3mm'den derin periodontal ceplerin bulunma sıklığı ile ilişkili olduğunu bildirmiştir [20]. Pham ve ark. ise yaptıkları bir çalışmayla dental plak, SK ve DKE'nin ağız kokusu oluşumuna neden olduğunu ileri sürmüşlerdir [21].

İki pozitif yüke sahip çinko iyonu, iki negatif yüklü sülfür radikaline bağlanarak USB oluşumunu azaltır. Çinko, daha az toksik olduğundan ve dişler üzerinde renklenme yapmadığından dolayı ağız kokusunun kontrolünde en çok incelenen bileşenlerden biridir. Schmidt ve Tarbet yaptıkları çalışma ile çinko içeren bir 
gargaranın hem OLS (\% 40 azalma) hem de USB (\% 80 azalma) değerlerini düşürmede 3 saat boyunca etkili olduğunu bildirmiştir [22]. Feng ve ark. yaptıkları randomize kontrollü bir klinik çalışma sonucunda kalay içeren diş macununun kontrol diş macununa göre sabah hissedilen kötü nefesi önlemede daha üstün olduğunu göstermişlerdir [23]. Çalışmamızda etken maddesi çinko ve kalay olan diş macunu kullanan hasta gruplarında periodontal parametrelerde ve ağız kokusu seviyelerinde belli bir düzeyde azalma olduğu gözlenmiştir. Bu gruplar birbirlerine göre kıyaslandıklarında aralarında ağız kokusu seviyelerini azaltma ve periodontal durumu iyileştirme açısından istatistiksel olarak anlamlı bir fark yoktur. Yalnızca Gí-t3 ortanca değerleri gruplara göre göre farkllık göstermektedir $(p<0,001)$. Her iki grupta da çalışmanın sonunda periodontal indeksler ve ağız kokusu seviyelerinde başlangıca göre daha iyi sonuçlar elde edilmiş olsa da çinko kalaydan ya da kalay çinkodan üstün değildir. Sonraki çalışmalarda bu parametreler ile ağız kokusu arasındaki ilişkinin detaylı olarak incelenmesi faydalı olacaktır.

\section{Sonuç}

Çalışma grubumuzun ağız kokusu farkındalık düzeyleri yüksektir. Ağız kokusu DMFT, ağız kuruluğu, ağız solunumu ve periodontal durum ile ilişkilidir. Çinko ve kalay içeren diş macunları ağız kokusu şikayeti olanlara önerilebileceği gibi bu konuyla ilgili daha fazla çalışmaya intiyaç olduğu kanısındayız.

\section{Çıkar çatışması / finansal destek beyanı}

Bu yazıdaki hiçbir yazarın herhangi bir çıkar çatışması yoktur. Yazının herhangi bir finansal desteği yoktur.

\section{Kaynaklar}

1. Tonzetich J. Production and origin of oral malodor: a review of mechanisms and methods of analysis. Journal of periodontology 1977; 48:13-20.

2. Scully $C$ et al. Breath odor: etiopathogenesis, assessment and management. European journal of oral sciences 1997; 105: 287-93.

3. Delanghe $\mathrm{G}$ et al. An inventory of patients' response to treatment at a multidisciplinary breath odor clinic. Quintessence international 1999; 30 (5).

4. Liu,X.N etal. Oral malodor-related parameters in the Chinese general population. Journal of clinical periodontology 2006; 33: 31-36.

5. De Boever, E.H, Loesche W.J. Assessing the contribution of anaerobic microflora of the tongue to oral malodor. The Journal of the American Dental Association 1995; 126: 1384-93.

6. Sanz M., Roldan S., Herrera D. Fundamentals of breath malodour. J Contemp Dent Pract 2001; 2:1-17.

7. Morita M., Musinski D.L., Wang H.L., Assessment of newly developed tongue sulfide probe for detecting oral malodor. Journal of clinical periodontology 2001; 28: 494-96.
8. Rosenberg M., McCulloch C.A. Measurement of oral malodor: current methods and future prospects. Journal of periodontology 1992; 63: 776-82.

9. Lu H.X et al. Characteristics of patients complaining of halitosis and factors associated with halitosis. Oral diseases 2014; 20: 787-95.

10. Quirynen M et al. Characteristics of 2000 patients who visited a halitosis clinic. Journal of clinical periodontology 2009; 36: 970-75.

11. Miyazaki $\mathrm{H}$ et al. Correlation between volatile sulphur compounds and certain oral health measurements in the general population. Journal of periodontology 1995; 66: 679-84.

12. Rosenberg $M$ et al. Self-assessment of oral malodor 1 year following initial consultation. Quintessence international 1999; 30(5).

13. Bornstein, M.M et al. Prevalence of halitosis in young male adults: a study in Swiss army recruits comparing self-reported and clinical data. Journal of periodontology 2009; 80: 24-31.

14. Iwanicka-Grzegorek $\mathrm{K}$ et al. Comparison of ninhydrin method of detecting amine compounds with other methods of halitosis detection. Oral diseases 2005; 11: 37-39.

15. Amir E, Shimonov R, Rosenberg M., Halitosis in children. The Journal of pediatrics, 1999; 134: 338-43.

16. Nalçacı R, Sönmez I.S. Evaluation of oral malodor in children. Oral Surgery, Oral Medicine, Oral Pathology, Oral Radiology, and Endodontology 2008. 106:384-88.

17. Çiçek $Y$ et al. Effect of tongue brushing on oral malodor in adolescents. Pediatrics international 2003; 45: 719-23.

18. Nalcaci R, Baran I. Oral malodor and removable complete dentures in the elderly. Oral Surgery, Oral Medicine, Oral Pathology, Oral Radiology, and Endodontology, 2008; 105: 5-9.

19. Suzuki $\mathrm{N}$ et al. The relationship between alcohol consumption and oral malodour. International dental journal 2009; 59: 31-34.

20. Tonzetich J. Oral malodour. An indicator of health status and oral cleanliness. Int Dent J 1978; 28: 309-19.

21. Pham T.A et al. Factors affecting oral malodor in periodontitis and gingivitis patients. Journal of investigative and clinical dentistry 2012; 3: 284-90.

22. Schmidt, N.F. and W.J. Tarbet, The effect of oral rinses on organoleptic mouth odor ratings and levels of volatile sulfur compounds. Oral Surgery, Oral Medicine, Oral Pathology 1978; 45: 876-83.

23. Feng $X$ et al. Breath malodor reduction with use of a stannouscontaining sodium fluoride dentifrice: a meta-analysis of four randomized and controlled clinical trials. Am J Dent 2010; 23: 27-31 